\title{
Nanotopographic Cell Culture Substrate: Polymer-Demixed Nanotextured Films Under Cell Culture Conditions
}

\author{
Jung Yul Lim, ${ }^{1}$ Christopher A. Siedlecki, ${ }^{2,3}$ and Henry J. Donahue ${ }^{4}$
}

\begin{abstract}
Modulating physical cell culture environments via nanoscale substrate topographic modification has recently been of significant interest in regenerative medicine. Many studies have utilized a polymer-demixing technique to produce nanotextured films and showed that cellular adhesion, proliferation, and differentiation could be regulated by the shape and scale of the polymer-demixed nanotopographies. However, little attention has been paid to the topographic fidelity of the polymer-demixed films when exposed to cell culture conditions. In this brief article, two polymer-demixing systems were employed to assess topographic changes in polymer-demixed films after fibronectin (FN) extracellular matrix protein adsorption and after incubation in phosphate-buffered saline at $37^{\circ} \mathrm{C}$. We showed that FN adsorption induced very small variations $(<2 \mathrm{~nm})$ to the polystyrene/polybromostyrene (PS/PBrS)-demixed nanoisland textures, not substantially altering the nanotopographies given by the polymer demixing. In addition, poly(L-lactic acid)/PS (PLLA/PS)-demixed nanoisland topographies using PLLA with $M_{\mathrm{w}}=50 \times 10^{3}$ did not show notable degradation up to day 24 .
\end{abstract}

Key words: cell culture; degradation; nanotopography; polymer demixing; protein adsorption

\section{Introduction}

$T^{\prime}$ HE MODUlation of physical cell culture environments via nanoscale substrate topographic modification has recently been of significant interest. ${ }^{1-4}$ Various methods, including oxidation and chemical etching, plasma and physical vapor deposition, electron-beam and nanoimprint lithography, self-organization and phase separation, have been utilized to produce nanotopographies. ${ }^{5}$ The use of nanotopographies for controlling cell behavior has a strong rationale. By replicating environments to which cells are exposed in vivo, one can provide biomimicking milieus as in vitro templates and elucidate fundamental mechanisms of cellular developmental, physiological, and pathological processes. ${ }^{1}$

Among various nanofabrication techniques, polymer demixing, one of the self-organization methods, has been used to fabricate thin film substrates. It can produce large-sized substrates covered with nanotopographic features cost effectively, as it adopts a simple spin-casting process using a polymer blend solution from two slightly immiscible polymers. ${ }^{6}$ Further, the shape and scale of the nanotopographic features can be controlled by adjusting the composition and concentration of the polymer blend solution, respectively, as previously demonstrated. ${ }^{7,8}$

Many studies, ${ }^{9-15}$ including ours, ${ }^{12-15}$ have shown that cell adhesion, proliferation, and differentiation can be regulated by polymer-demixed nanotextures. Of particular interest, we showed that polymer-demixed nanotopographies can affect focal adhesion kinase signaling, ${ }^{12}$ cell mechanotransduction under fluid flow, ${ }^{14}$ and mesenchymal stem cell differentiation toward osteogenesis. ${ }^{15}$ Even considering these data, relatively less attention has been paid to the topographic fidelity of polymer-demixed films during cell culture. Since these studies have dealt with topographies at the nanoscale, one question is whether adsorbed extracellular matrix (ECM) proteins will alter given nanotopographies. Another question that may arise, especially when polymer demixing uses a biodegradable polymer as one of the components, ${ }^{8}$ is whether the topographies will be altered due to degradation. To address these questions, two polymer-demixing systems were employed in this study. The films were assessed in topographic changes (1) after ECM protein adsorption and (2) after incubation in phosphate-buffered saline (PBS) at $37^{\circ} \mathrm{C}$.

\footnotetext{
${ }^{1}$ Department of Mechanical and Materials Engineering, University of Nebraska-Lincoln, Lincoln, Nebraska.

${ }^{4}$ Division of Musculoskeletal Sciences, Department of Orthopaedics and Rehabilitation, and Departments of ${ }^{2}$ Bioengineering and ${ }^{3}$ Surgery, College of Medicine, Pennsylvania State University, Hershey, Pennsylvania.
} 


\section{Materials and Methods}

\section{Polymer-demixed nanotextured films}

Two types of nanotopographic films were produced using polymer demixing following our published protocols. ${ }^{7,8}$ Polystyrene/polybromostyrene (PS/PBrS)-demixed nanoisland films were produced at 40/60 (w/w) PS/PBrS composition and $1 \%(w / w)$ total polymer concentration. As a template for assessing potential degradation, poly(L-lactic acid)/PS (PLLA/PS) demixing was done at 70/30 w/w PLLA/PS composition and $0.5 \%(\mathrm{w} / \mathrm{w})$ polymer concentration. The same materials and spin-casting conditions as previous studies $^{7,8}$ were used, that is, molecular weights $\left(M_{\mathrm{w}}\right)$ were PS= $289 \times 10^{3}, \mathrm{PBrS}=65 \times 10^{3}$, and PLLA $=50 \times 10^{3}$ (PS and PBrS from Sigma, PLLA from Polysciences), and spin casting was performed at $4000 \mathrm{rpm}$ for $30 \mathrm{~s}$ using a Specialty Coating Systems P6700 spincoater. For the PS/PBrS system, demixed topographic films were annealed for $2 \mathrm{~h}$ at $130^{\circ} \mathrm{C}$. This was above the glass transition temperature $\left(T_{\mathrm{g}}\right)$ of PS $\left(103^{\circ} \mathrm{C}\right)$ but below the $T_{\mathrm{g}}$ of $\mathrm{PBrS}\left(150^{\circ} \mathrm{C}\right)$, which was to make PS segregate to the film surface. ${ }^{7}$

\section{Topography measurement after fibronectin adsorption}

Single protein adsorption on PS/PBrS-demixed nanotopographic films was performed using fibronectin (FN). The adsorption of FN from a PBS solution $(50 \mu \mathrm{g} / \mathrm{mL})$ was performed for $30 \mathrm{~min}$. The films were then washed, dried, and assessed by an atomic force microscope (AFM; Nanoscope IIIa) in the tapping mode to measure the topographic height information and in the phase mode to obtain information on chemical composition.

\section{Topography and $\mathrm{pH}$ measurement after incubation in $\mathrm{PBS}$ at $37^{\circ} \mathrm{C}$}

PLLA/PS-demixed nanotextured films were incubated in PBS at $37^{\circ} \mathrm{C}$ using a regular incubator. After 12 and 24 days of incubation, changes in $\mathrm{pH}$ were measured using a $\mathrm{pH}$ meter, while the films were still maintained in PBS. On the same days, films were taken out of the incubator and dried for AFM measurement (tapping mode). Surface roughness $(R)$ was quantified using three different samples. It should be noted that PBS was not changed throughout the degradation tests.

\section{Results}

\section{Effect of FN adsorption on topography of polymer-demixed films}

To assess topographic changes after protein adsorption, PS/PBrS-demixed films were adsorbed with FN and measured by AFM. PS/PBrS $(40 / 60 \mathrm{w} / \mathrm{w})$ demixing at $1 \%$ concentration resulted in topographies with randomly distributed islands. The average island height was $26.2 \pm 4.0 \mathrm{~nm}$ (Fig. 1C). This falls on the interpolated island height from our previous study that showed 11, 38, and $85 \mathrm{~nm}$ average island heights at $0.5 \%, 2 \%$, and $5 \%$ total polymer concentrations, respectively. ${ }^{7} \mathrm{FN}$ adsorption did not change the overall shape of PS/PBrS-demixed nanoislands (Fig. 1B). In the section view, FN adsorption at $50 \mu \mathrm{g} / \mathrm{mL}$ induced very small changes in nanoisland texture. The average magnitude of variations from FN adsorption was $1.2 \pm 0.7 \mathrm{~nm}$, which is less than the standard deviation of the original island

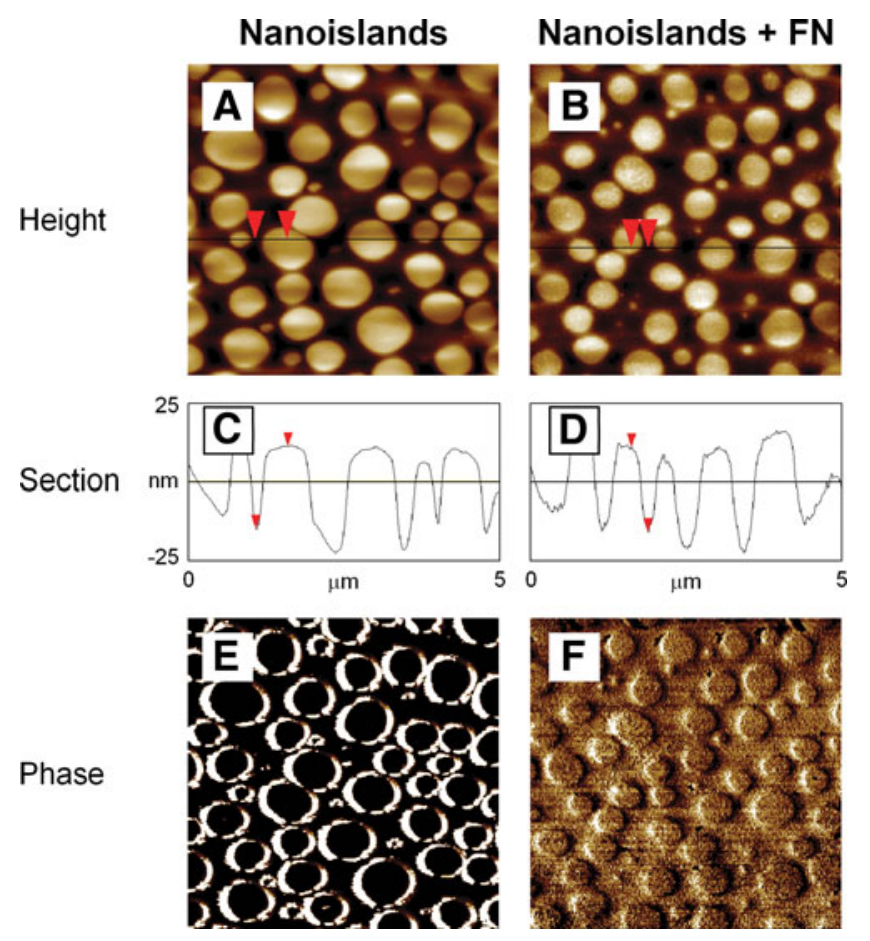

FIG. 1. Atomic force microscope (AFM) measurement of polystyrene/polybromostyrene (PS/PBrS)-demixed films, (A, C, E) without or (B, D, F) with fibronectin (FN) adsorption. PS/PBrS $(40 / 60 \mathrm{w} / \mathrm{w})$ demixing was performed at a $1 \%$ total polymer concentration. AFM (Nanoscope IIIa; Digital Instruments) was used in tapping mode under ambient condition to obtain height $(\mathbf{A}, \mathbf{B})$ and section $(\mathbf{C}, \mathbf{D})$ information. In addition, AFM was used in the phase mode $(\mathbf{E}, \mathbf{F})$ to assess the difference in chemical composition. FN adsorption at $50 \mu \mathrm{g} / \mathrm{mL}$ produced uniform FN coverage throughout the nanoisland surface, and induced very small variations $(1.2 \pm 0.7 \mathrm{~nm})$ in height to the given nanotopographies. Red arrows show measurements from island top to bottom.

height. In the AFM phase mode, bare PS/PBrS-demixed films showed consistent phase offset across the surface other than island perimeters (Fig. 1E). This suggests uniform chemistry formation except the ring-shaped portions. The ring-shaped difference may, however, be an artifact from AFM scanning (see more in the Discussion section). For FN-adsorbed PS/ PBrS-demixed films, the phase AFM image showed consistent phase offset throughout the surface (Fig. 1F), indicating that FN adsorption at a given concentration uniformly covered the entire nanoisland topographies.

\section{Effect of cell culture relevant incubation on topography and $\mathrm{pH}$ of polymer-demixed films}

PS/PBrS-demixed films are not degradable, whereas some polymer-demixing systems have employed biodegradable polymers, for example, PLLA. ${ }^{8}$ The objective was for the potential use of these films as substrates for drug delivery (however, limited reports have been found in the literature regarding this issue). The degradation of bioabsorbable polymers is largely determined by their molecular weights. ${ }^{16}$ In this study, we performed degradation tests using our published polymer-demixing system (PLLA $M_{\mathrm{w}}=50 \times 10^{3}$ in PLLA/PS demixing) ${ }^{8,15}$ to check potential topographic 
changes in these nanotextures during cell culture. Since in vitro cell differentiation assays usually last for several weeks, ${ }^{15}$ we employed an incubation time up to 24 days. The overall shape of the nanoislands produced by PLLA/ PS demixing was not substantially altered by incubation at $37^{\circ} \mathrm{C}$ until day 24 (Fig. 2). Quantified roughness $(R)$ of the surfaces showed a trend of gradual increase, $6.1 \pm 1.3 \mathrm{~nm}$, $6.3 \pm 1.8 \mathrm{~nm}$, and $6.4 \pm 1.2 \mathrm{~nm}$ on day 0,12 , and 24 , respectively. However, these changes did not reach statistical significance when assessed by analysis of variance $(n=3)$. The $\mathrm{pH}$ measured with time did not significantly change, either, $\mathrm{pH}$ $8.01 \pm 0.024,8.02 \pm 0.023$, and $8.01 \pm 0.028$ on day 0,12 , and 24 , respectively $(n=3)$.

\section{Discussion}

We demonstrated that key characteristics of polymerdemixed nanotopographies, that is, nanoisland shape and scale, are maintained even after ECM protein adsorption and cell culture relevant incubation. For PS/PBrS-demixed films, $\mathrm{FN}$ adsorption at $50 \mu \mathrm{g} / \mathrm{mL}$ induced very small height variations to the given nanoisland textures. For PLLA/PS demixing with PLLA $M_{\mathrm{w}}=50 \times 10^{3}$, nanotopographies and $\mathrm{pH}$ were not significantly altered after up to 24 days of incubation. Together, these results at least partly address one of the fundamental questions on nanotopographic regulation of cells, that is, whether nanotopographic cell function control is dominantly mediated by other cell-substrate interfacial phenomena. Under the experimental conditions employed, we conclude that nanotopographic regulation of cells is not significantly affected by ECM protein adsorption or changes due to film degradation.

One advantage of polymer demixing is that the nanotopography effect on cells can be examined, while surface chemistry is maintained unchanged. PS/PBrS-demixed and then annealed nanotextures have a top film surface chemistry of PS due to selective surface segregation of PS, ${ }^{7,17}$ which has been observed by X-ray photoelectron spectroscopy. It was proposed that the lower surface energy component (PS) segregates to the air-film interface to minimize interfacial free en-

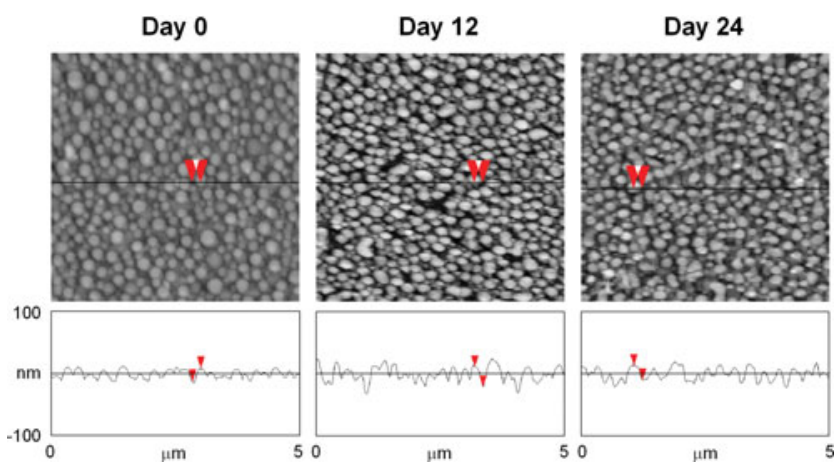

FIG. 2. AFM measurement of poly(L-lactic acid)/PS (PLLA/ PS)-demixed films after incubation in phosphate-buffered saline (PBS) at $37^{\circ} \mathrm{C}$. PLLA/PS $(70 / 30 \mathrm{w} / \mathrm{w})$ demixing was performed at a $0.5 \%$ total polymer concentration. On each day, the film was taken out of PBS, dried, and measured by AFM using the tapping mode. Roughness parameters $(R)$ on each day were quantified using the AFM software. The change in $R$ did not show statistical significance (see the main text). Red arrows show measurements from island top to bottom. ergy. Considering this, it is not clear at this stage whether the ring-shaped difference observed in AFM phase mode (Fig. $1 \mathrm{E})$ is a true phase difference or an AFM artifact. It may possibly be an edge artifact, as many rings showed an asymmetric structure. It should be noted that in the PLLA/PS demixing developed in our previous study, PLLA segregated to the film surface even without annealing. ${ }^{8}$

Regardless of the ring structure observed in the AFM image of bare PS/PBrS-demixed film, FN showed welldistributed adsorption throughout the nanoisland topographies (Fig. 1F) and did not substantially alter the original nanotopographic texture in either island shape or height (Fig. 1A, B, C, D). This suggests that nanotopography effects on cells from polymer-demixed nanotextures, observed in our previous studies, ${ }^{12-15}$ may be independent of adsorbed ECM proteins. In a recent study using FN adsorption on PLLA/PSdemixed films at lower FN concentrations, FN did not uniformly cover the substrate. ${ }^{18}$ This study reported that FN adsorption at $2 \mu \mathrm{g} / \mathrm{mL}$ resulted in $20-25 \%$ surface coverage. At this low concentration, interestingly, $\mathrm{FN}$ adsorption on PLLA/PS-demixed films was more on nanoisland peaks. ${ }^{18}$ In contrast, our results indicate that $50 \mu \mathrm{g} / \mathrm{mL}$ was sufficient to cover the entire PS/PBrS-demixed nanotextures. In addition to the solution protein concentration, protein adsorption is also affected by substrate characteristics, for example, chemistry. Sousa et al. ${ }^{19}$ assessed $\mathrm{FN}$ adsorption on $\mathrm{TiO}_{2}$ surfaces with varying roughnesses. They used techniques to quantify FN adsorption, including FN radiolabeling with ${ }^{125} \mathrm{I}$ and detection by radioimmunoassay and ellipsometry, after FN adsorption. They demonstrated that even at a high FN concentration of $70 \mu \mathrm{g} / \mathrm{mL}$, the amount of $\mathrm{FN}$ adsorption on $\mathrm{TiO}_{2}$ surfaces was less than that of the ideal amount for the FN monolayer $\left(1750-41,000 \mu \mathrm{g} / \mathrm{m}^{2}\right) .{ }^{20}$ As a result, FN adsorption at $70 \mu \mathrm{g} / \mathrm{mL}$ on $\mathrm{TiO}_{2}$ did not show uniform monolayertype adsorption but showed a clustered shape. This was confirmed by AFM, as the AFM phase images showed two distinct phases (FN and $\mathrm{TiO}_{2}$ surface). ${ }^{19}$ Although rigorous assays (radioimmunoassay or ellipsometry) for quantifying FN adsorption amount were not performed in this study, uniform FN coverage on PS/PBrS-demixed surfaces could be clearly seen in the AFM phase image, but it is not clear at this stage whether this FN adsorption is monolayer or multilayer adsorption. One more thing to be noted is that since we performed AFM tests of FN-adsorbed films after drying, topographic height fluctuation by $\mathrm{FN}$ adsorption may be slightly different for the wet state. However, for the same FN adsorption conditions $(50 \mu \mathrm{g} / \mathrm{mL}, 30 \mathrm{~min})$, Sousa et al. ${ }^{19}$ showed that surface roughness change due to drying was quite small (roughness was about $0.2-1 \mathrm{~nm}$ higher for the wet state compared with that of the dried state). This suggests that topographic height changes from drying would still be within the standard deviation of the original island height for nanotopographies employed.

We showed that PLLA at a given $M_{\mathrm{w}}$ did not undergo notable degradation up to day 24 , as noted by overall topographic shape, measured roughness parameter, and $\mathrm{pH}$ change. However, we cannot guarantee under this set of experimental conditions that there was no degradation related to molecular phenomena such as hydrolysis. For bulk polymer samples, several techniques are useful to assess the degradation behavior, including measurement of molecular weight and polydispersity index by gel permeation 
chromatography, measurement of mechanical properties, and so on. For polymers undergoing degradation in solution, timedependent static light scattering may also be used to reveal the degradation mechanisms, for example, random degradation of single and multiple stranded coils or stripping of sidechains. ${ }^{21}$ Although our study assessing changes in topography and $\mathrm{pH}$ showed apparent degradation data that are useful for evaluating cell culture conditions, further tests using longer degradation times and other techniques would be required to reveal the thorough degradation profile and mechanisms. However, these are beyond the scope of the current work.

The PLLA/PS-demixing system may have a potential to be used as a film template for drug delivery if lower $M_{\mathrm{w}}$ PLLA is used. Ideally, polymer-demixed nanotopographic films would initially induce enhanced cell adhesion and growth (as reported in our previous studies ${ }^{7,8}$ ), and then, with the initiation of PLLA degradation, an embedded drug (e.g., growth factor) could be released to stimulate later stage cell function, for example, differentiation. While fine tuning of the degradation profile would be required, such nanotextured drug delivery films may be considered interesting new biomaterials.

\section{Acknowledgments}

The authors acknowledge AO Foundation Research Grant (S-10-7L), NE DHHS Stem Cell Research Grant (2011-05), AHA Scientist Development Grant (12SDG12030109) to J.Y.L., and NIH R01 AR054937 to H.J.D.

\section{Author Disclosure Statement}

No competing financial interests exist.

\section{References}

1. Kim DH, Provenzano PP, Smith CL, et al. Matrix nanotopography as a regulator of cell function. J Cell Biol. 2012;197:351360.

2. Guduru D, Niepel M, Vogel J, et al. Nanostructured material surfaces: preparation, effect on cellular behavior, and potential biomedical applications: a review. Int J Artif Organs. 2011;34:963-985.

3. Anselme K, Davidson P, Popa AM, et al. The interaction of cells and bacteria with surfaces structured at the nanometre scale. Acta Biomater. 2010;6:3824-3846.

4. Bettinger CJ, Langer R, Borenstein JT. Engineering substrate topography at the micro- and nanoscale to control cell function. Angew Chem Int Ed Engl. 2009;48:5406-5415.

5. Variola F, Brunski JB, Orsini G, et al. Nanoscale surface modifications of medically relevant metals: state-of-the art and perspectives. Nanoscale. 2011;3:335-353.

6. Dalby MJ, Pasqui D, Affrossman S. Cell response to nanoislands produced by polymer demixing: a brief review. IEE Proc Nanobiotechnol. 2004;151:53-61.

7. Lim JY, Hansen JC, Siedlecki CA, et al. Human foetal osteoblastic cell response to polymer-demixed nanotopographic interfaces. J R Soc Interface. 2005;2:97-108.

8. Lim JY, Hansen JC, Siedlecki CA, et al. Osteoblast adhesion on poly(L-lactic acid)/polystyrene demixed thin film blends: effect of nanotopography, surface chemistry, and wettability. Biomacromolecules. 2005;6:3319-3327.

9. Berry CC, Dalby MJ, McCloy D, et al. The fibroblast response to tubes exhibiting internal nanotopography. Biomaterials. 2005;26:4985-4992.

10. Dalby MJ, McCloy D, Robertson M, et al. Osteoprogenitor response to semi-ordered and random nanotopographies. Biomaterials. 2006;27:2980-2987.

11. Berry CC, Dalby MJ, Oreffo RO, et al. The interaction of human bone marrow cells with nanotopographical features in three dimensional constructs. J Biomed Mater Res A. 2006;79:431-439.

12. Lim JY, Dreiss AD, Zhou Z, et al. The regulation of integrinmediated osteoblast focal adhesion and focal adhesion kinase expression by nanoscale topography. Biomaterials. 2007;28: 1787-1797.

13. Hansen JC, Lim JY, Xu LC, et al. Effect of surface nanoscale topography on elastic modulus of individual osteoblastic cells as determined by atomic force microscopy. J Biomech. 2007;40:2865-2871.

14. Salvi JD, Lim JY, Donahue HJ. Increased mechanosensitivity of cells cultured on nanotopographies. J Biomech. 2010;43: 3058-3062.

15. Lim JY, Loiselle AE, Lee JS, et al. Optimizing the osteogenic potential of adult stem cells for skeletal regeneration. J Orthop Res. 2011;29:1627-1633.

16. Tsuji H. Poly(lactide) stereocomplexes: formation, structure, properties, degradation, and applications. Macromol Biosci. 2005;5:569-597.

17. Dalby MJ, Riehle MO, Johnstone $\mathrm{H}$, et al. In vitro reaction of endothelial cells to polymer demixed nanotopography. Biomaterials. 2002;23:2945-2954.

18. Pérez-Garnes M, González-García C, Moratal D, et al. Fibronectin distribution on demixed nanoscale topographies. Int J Artif Organs. 2011;34:54-63.

19. Sousa SR, Manuela Bra's M, Moradas-Ferreira $P$, et al. Dynamics of fibronectin adsorption on $\mathrm{TiO}_{2}$ surfaces. Langmuir. 2007;23:7046-7054.

20. Rouxhet L, Duhoux F, Borecky O, et al. Adsorption of albumin, collagen, and fibronectin on the surface of poly (hydroxybutyrate-hydroxyvalerate) (PHB/HV) and of poly (epsilon-caprolactone) (PCL) films modified by an alkaline hydrolysis and of poly(ethylene terephtalate) (PET) track-etched membranes. J Biomater Sci Polym Ed. 1998;9:1279-1304.

21. Ganter JL, Sabbi JC, Reed WF. Real-time monitoring of enzymatic hydrolysis of galactomannans. Biopolymers. 2001;59: 226-242.

Address correspondence to: Henry J. Donahue, PhD Division of Musculoskeletal Sciences Department of Orthopaedics and Rehabilitation College of Medicine

Pennsylvania State University 500 University Drive Hershey, PA 17033

E-mail: hdonahue@psu.edu 